4 Laflin $M$. Intereaction of pancuronium and corticosteroids. Anesthesiology 1977; 47: 471-2.

5 Durant N, Briscole J, Katz $R$. The effects of acute and chronic hydrocortisome treatment of neuromuscular blockade in the anesthetized cat. Anesthesiology 1984; 61: 144-50.

\section{Estimation of blood loss in the operating room}

To the Editor:

A common way to estimate blood loss in the operating room is to subtract the amount of irrigation fluid used from the total volume of blood and fluid in the suction bottle. This technique requires a record of irrigation fluids and this may lead to omissions or inaccuracy.

We wish to remind readers of the usefulness of the micro-haematocrit method to determine the packed cell volume (PCV) of the blood and fluid in the suction bottle, and therefore to estimate blood loss. The following simple calculation estimates the amount of blood in the fluid:

\section{Blood loss}

$$
=\frac{\text { volume in the suction bottle } \times \text { suction } \mathrm{PCV}}{\text { patient PCV }}
$$

Many methods are used by surgeons and anaesthetists to estimate blood loss. Accurate methods are more complex and therefore less likely to be easily applied. ${ }^{1-4}$ The method we describe has its own inbuilt errors. The suction bottle sample must be well mixed or the formation of clot and effects of gravity will produce an inaccurate sample. The assumption that the $\mathrm{PCV}$ of the patient stays constant throughout the procedure is erroneous as a decreasing haematocrit would tend to overestimate the blood loss. At the same time haemolysis from trauma and irrigating fluids tends to give an erroneously low PCV value for the suction fluid and this would underestimate the amount of blood loss. Blood that is not suctioned must be measured by other means.

\section{Hang C. Ha MD}

Robert L. Weiler B SC FRCPC

Department of Anaesthesia

University Hospital

Saskatoon, Saskatchewan

S7N 0X0

\section{REFERENCES}

1 Marshall M, Bird T. Blood Loss and Replacement. Edward Amold, London, 1983.

2 Mainland JF. A simple photo-electric method for the estimation of blood loss. Br J Anaesth 1966; 38 : 76-8.

3 LeVeen HH, Rubricius $J L$. Continuous, automatic, electronic determinations of operative blood loss. Surg Gynecol Obstet 1958; 368-74.

4 Roller NN, King $O H$. A simple way to determine the amount of blood loss during oral surgery. J Oral Maxillo-Facial Surg 1983; 411:618-20.

\section{Ketamine induction for a patient with hyperinsulinism treated with oral diazoxide}

To the Editor:

The usefulness of oral diazoxide in the management of hyperinsulinism, because of its direct inhibitory action on release of pancreatic insulin, is well documented. ${ }^{1}$ Diazoxide is a nondiuretic benzothiadiazine derivative and has potent vascular dilating activity. Burch and McLeskey ${ }^{2}$ reported marked hypotensive episodes related to thiopentone administration in two patients with hyperinsulinism treated with oral diaxoxide. They postulated three mechanisms of the untoward drug interactions between diazoxide and thiopentone: (1) displacement of diazoxide from protein binding sites by thiopentone; (2) increased unbound thiopentone due to preoccupation of binding sites by diazoxide; (3) a combination of the first two mechanisms, resulting in an additive effect on depression of blood pressure.

Ketamine, instead of thiopentone, might be the intravenous agent of choice for induction of anaesthesia in patients with hyperinsulinism treated with oral diazoxide, because of its cardiovascular-stimulating properties and limited plasma protein binding. ${ }^{3}$ We wish to report our experience with the use of ketamine for induction.

A 1-year 8-month old $12 \mathrm{~kg}$ boy with hyperinsulinism, treated with oral diazoxide $10 \mathrm{mg} \cdot \mathrm{kg}^{-1}$. day $^{-1}$ was scheduled for pancreatectomy. Diazoxide was continued until the morning of the surgery, because of the previous profound hypoglycaemic episodes upon discontinuation of diazoxide. 